\title{
Level of conus medullaris in term and preterm neonates
}

\author{
F Şahin, M Selçuki, N Ecin, A Zenciroğlu, A Ünlü, F Yilmaz, N Maviş, S Saribaş
}

\begin{abstract}
Aims-To compare the levels of conus medullaris in preterm and term neonates; to show the time of ascent to normal; and to evaluate the babies with low conus medullaris levels for tethered cord syndrome.

Methods-Levels were assessed using ultrasonography in 41 preterm and 64 term neonates.

Results-In the preterm group the conus medullaris level in one infant $(2.4 \%)$ was below $\mathbf{L} 4$. In three infants $(7.2 \%)$ it was between L2 and L3 and in 37 infants $(90.4 \%)$ it was above $\mathrm{L} 2$. In the term group it was below $L 4$ in one baby $(1.6 \%)$, between $L 2$ and $L 3$ in four (6.3\%), and above $L 2$ in 57 babies (92.1\%). The difference in the conus medullaris levels between term and preterm neonates and genders was not significant. Two patients, one with a conus medullaris level at L4-L5, and the other at L2-L3, had Down's syndrome.

Conclusion-The ascent of conus medullaris seems to occur early in life. It is important to follow up patients with conus medullaris levels at or below the 4th lumbar vertebra for the development of tethered cord syndrome.

(Arch Dis Child 1997;77:F67-F69)
\end{abstract}

Keywords: conus medullaris; spinal cord; tethered cord; ultrasonography

Neonatal Intensive Care Unit, Sami Ulus Children's Hospital,

Ankara,

Turkey

F Sahin

A Zenciroğlu

S Saribaş

Department of

Neurosurgery, Division

of Paediatric

Neurosurgery,

University of Ankara

School of Medicine

M Selçuki

A Ünlü

Radiology Unit, Sami Ulus Children's Hospital

N Ecin

F Yilmaz

$\mathrm{N}$ Maviş

Correspondence to:

Dr Figen Sahin,

Oyak Sitesi 7, Blok No 7,

Cankaya 08550 Ankara,

Turkey.

Accepted 12 February 1997 menstrual date or by antenatal ultrasonography. In the preterm babies, corrected gestational ages were used for the evaluation of conus medullaris if ultrasound examination could not be done immediately because of the clinical instability of the babies.

Ultrasound examination was performed using an SSA 250 A machine (Toshiba, Tokyo) with a $7.5 \mathrm{MHz}$ linear transducer. Infants were examined in the prone, gently flexed position. Both longitudinal and transverse sections were performed and 5th lumbar vertebra (L5) was identified by finding the lumbosacral junction and angulation at this point. The conus was marked at the end of tapering distal spinal cord which is hypoechoic and its level determined by the adjacent intervertebral disk space.

The $\chi^{2}$ test was used for statistical analysis.

\section{Results}

Spinal ultrasonography was performed on a total of 106 patients ( 48 girls and 58 boys). In a patient with cleft lip and cleft palate and congenital hydrocephalus, conus medullaris was found below the 4 th lumbar vertebra (L4), but this patient was not included in this study because of his neural defect. Of the other 105 patients, the gestational ages of 41 babies were smaller than or equal to 37 weeks, and in 64 patients gestational age was above 37 weeks.

The conus medullaris levels of these patients are shown in table 1. Conus medullaris ended at the level between the first and second lumbar vertebrae (L1-L2) in $88 \%$ and $78 \%$ of preterm and term babies, respectively. In the preterm group three patients $(7.2 \%)$ had conus medullaris between the second and third lumbar vertebrae (L2-L3) and in one patient $(2.4 \%)$ it was at the L4-L5 level. The gestational ages of these patients were $37,36,34$ and 37 weeks, respectively. In one patient the level of conus medullaris, at L2-L3 at the age of 34 weeks, had ascended to L1-L 2 by the age of 42 weeks. Conus medullaris was also found at the L1-L2 level in premature babies with the smallest for gestational age patients (fig 1). The difference between gestational ages and conus medullaris levels was not significant $(\mathrm{P}>0.05)$.

In the term babies, conus medullaris ended at $\mathrm{L} 4-\mathrm{L} 5$ in one patient $(1.6 \%)$ and at $\mathrm{L} 2-\mathrm{L} 3$ in four $(6.3 \%)$. In the other patients $(92.1 \%)$ conus medullaris was above L2 level. The patient with conus medullaris at L4-L5 had severe hyponatremia and acute renal failure and died before the control ultrasonography could be carried out (fig 2).

Among the preterms two neonates, one with conus medullaris level at L4-L5 and the other with L2-L3, had Down's syndrome. The first 
Table 1 Termination value of conus medullaris in premature and term neonates

\begin{tabular}{lccc}
\hline Level of conus medullaris & Premature $n(\%)$ & Term $n(\%)$ & Total \\
\hline T12-L1 & $0(0)$ & $5(7.8)$ & $5(4.8)$ \\
L1 & $1(2.4)$ & $2(3.1)$ & $3(2.8)$ \\
L1-L2 & $36(88.0)$ & $50(78.1)$ & $86(81.9)$ \\
L2 & $0(0)$ & $2(3.1)$ & $2(1.9)$ \\
L2-L3 & $3(7.2)$ & $4(6.3)$ & $7(6.7)$ \\
Below L4 & $1(2.4)$ & $1(1.6)$ & $2(1.9)$ \\
Total & $41(100)$ & $64(100)$ & $105(100)$ \\
\hline
\end{tabular}

$\mathrm{P}>0.05$.

Table 2 Conus medullaris values in female and male infants

\begin{tabular}{lccc}
\hline Level of conus medullaris & Female $n(\%)$ & Male $n(\%)$ & \multicolumn{1}{c}{ Total } \\
\hline T12-L1 & $2(4.2)$ & $3(5.3)$ & $5(4.8)$ \\
L1 & $0(0)$ & $3(5.3)$ & $3(2.9)$ \\
L1-L2 & $42(87.5)$ & $44(77.2)$ & $86(81.9)$ \\
L2 & $0(0)$ & $2(3.5)$ & $2(1.9)$ \\
L2-L3 & $3(6.2)$ & $4(7.0)$ & $7(6.6)$ \\
Below L4 & $1(2.1)$ & $1(1.7)$ & $2(1.9)$ \\
Total & $48(100)$ & $57(100)$ & $105(100)$ \\
\hline
\end{tabular}

$\mathrm{P}>0.05$. canal. ${ }^{4}$ But the precise timing of this ascent is still a matter of debate. In a study of 184 children ranging in age from newborn to 20 years, the range of conus levels was reported as T12 to L3. The range for the $0-2$ year old group was T12 to L2-L3 with an average of L1-L2. ${ }^{5}$ They concluded that a conus level at L2-L3 or above should be considered normal at any age. In another study of preterm and term neonates, the mean position of the conus was found midway between the L1-L2 disc and midpoint of the L2 body. ${ }^{6}$ A small but significant rise in position was identified from 33 to 42 postconceptual weeks. In our study the mean level of conus medullaris was L1-L2 both in premature and term babies. There were no significant differences between these two groups. Studies have shown that the most rapid ascent of the conus medullaris occurs in the first half of gestation, especially between $9-16$ weeks. ${ }^{3}{ }^{6}$ The gestational age of the youngest newborn baby in our study was 31 weeks, suggesting that the ascent of the conus medullaris occurs before that age. But as the number of small premature babies in our study is limited, studies with larger numbers of patients are required.

In previous studies racial and sex differences in the level of the termination of the spinal cord have been reported. ${ }^{7}$ But we found no difference in the endpoints of spinal cords between boys and girls. In a study by Vettivel in 1991 a sex difference was not observed either. ${ }^{7}$

Several radiological techniques, such as computed tomography and magnetic resonance imaging, can be used to determine the level of the spinal cord or congenital abnormalities. ${ }^{8}$ But these techniques are difficult to perform, especially in young children as general anaesthesia may be required to keep them immobile. For neonates and young infants in whom the ossification of vertebral bodies is incomplete, ultrasonography of the spine is a safe, easy, and non-invasive method and is therefore preferable. ${ }^{9} 10$

As the normal level of the conus medullaris does not extend below the third lumbar vertebra, the patients with lower levels should be examined for tethered cord syndrome. The tethered cord syndrome is a clinical entity manifest by progressive motor and sensory changes in the legs, incontinence, back or leg pain and scoliosis. Symptoms are caused by pressure on the spinal cord and nerve roots. ${ }^{11}$ Impaired blood flow, function, and metabolism have been observed in the traumatised or compressed cord. Surgical untethering should be done not only to prevent the progress of the neurological signs and symptoms, but also to alleviate them. ${ }^{12}$ In our study, only in two patients was the conus medullaris below the level of L3. One of these was a term baby with severe hyponatremia and acute renal failure. Spinal ultrasonography was performed only once before he died. The other patient, a 37 week gestational age baby with Down's syndrome, died at home before a control ultrasound scan could be performed. These two patients were therefore not evaluated for tethered cord syndrome. 
In our study another patient with Down's syndrome had the conus medullaris level at L2-L3. Although this is in the normal range, it was lower than average. In Down's syndrome associated anomalies related to various organ systems are common and incomplete fusion of vertebral arcs is seen in $37 \%$ of these patients. ${ }^{13}$ Although we could not find any report of a correlation between Down's syndrome and low lying conus medullaris, our findings in these two patients have led us to consider the possible association of these two pathological entities.

We conclude that conus medullaris level is not different in preterm and term neonates, and it is above the level of L2 in more than $90 \%$ of babies. There does not seem to be any difference in the level of conus medullaris between female and male infants. It is important to follow up babies whose conus medullaris is below L2 to eliminate the tethered cord syndrome.

We thank Dr Tahsin Teziç, director of the Sami Ulus Children's Hospital, for his support and cooperation during the study.
1 Wolf $S$. The conus medullaris: time of ascendance to normal level. Pediatr Radiol 1992;22:590-2.

2 DiPietro M. The conus medullaris: Normal US findings throughout childhood. Pediatr Radiol 1993;188:149-53.

3 Barson AJ. The vertebral level of termination of the spinal cord during normal and abnormal development. f Anat 1970;106:489-97.

4 Ghazi SR. Allometric growth of the spinal cord in relation to the vertebral column during prenatal and postnatal life in the sheep. F Anat 1994;185:427-31.

5 Award JC. MR Imaging Determination of the location of the normal conus medullaris throughout childhood. $\mathrm{Am} \mathcal{F}$ Radiol 1989;152:1029-32.

6 Rowland Hill CA. Ultrasound determination of the normal location of the conus medullaris in neonates. Am F Neonat Radiol 1995;16:469-72.

7 Vettivel S. Vertebral level of termination of the spinal cord in human fetuses. F Anat 1991;179:149-61.

8 O'Connor JF. Radiologic manifestations of congenital anomalies of the spine. Radiol Clin North Am 1991;29:40729.

9 Gusnard DA. Ultrasonic anatomy of the normal neonatal and infant spine: correlation with cryomicrotome sections and CT. Neuroradiology 1986;28:493-511.

10 Award JC. Sonography of the caudal spine and back: congenital anomalies in children. $A m \mathcal{F}$ Radiol 1984;142:1229-42.

11 Lyons-Jones K. Smith's recognizable pattern of human malformation. 4th edn. Philadelphia: W.B Saunders Co, 1988:10-3.

12 Yamada S. Pathophysiology of tethered cord syndrome. f Neurosurg 1981;54:494-503.

13 Jacobson RI. Congenital structural defects. In: Swaiman KF, ed. Pediatric Neurology: Principles and practice. St.Louis: CV Mosby Co, 1989:320-1. 